\title{
Generation and immunogenicity assessment of ELPylated virus-like particles of porcine circovirus type 2
}

Yangyang Li ${ }^{1}$, Yajie Wang ${ }^{1}$, Jian Cheng ${ }^{1}$, Xiaohui Zhou ${ }^{1}$, Huipeng Lu $^{1}$, Xinyu Zhang ${ }^{1}$, Xiaoli Xia ${ }^{1}$ and Huaichang Sun ${ }^{1,2^{*}}$

\begin{abstract}
Background: Porcine circovirus type 2 (PCV2) is an economically important pathogen affecting swine industry worldwide. The production of current PCV2 vaccines is time-consuming and expensive. Elastin-like polypeptides (ELP) undergo temperature-dependent inverse phase transition and ELPylated proteins can be purified simply by inverse transition cycling (ITC).

Methods: The Cap protein of PCV2b, together with the virus neutralizing (VN) epitopes of PCV2a, PCV2d and PCV2e, was expressed in E. coli as an ELPylated protein, and purified by ITC in the presence of mild detergents. For the control purpose, the Cap protein was also expressed as a His-tagged protein and purified by nickel affinity chromatography. The formation of ELPylated VLP (ELP-VLP) and His-tagged VLP (VLP) was revealed by transmission electron microscopy. Mice were immunized two times with the two forms of VLP and the antigen-specific $\lg G$ antibody, VN antibody, cytokine responses and immunoprotection against PCV2 challenge were compared.

Results: ELPylated Cap protein was expressed as a soluble protein and purified to $94.3 \%$ purity by ITC in the presence of 1\% Triton X-100 and $0.5 \mathrm{M}$ urea. His-tagged Cap fusion protein was expressed as insoluble inclusion bodies and purified to $90 \%$ purity under denatured conditions. The two purified fusion proteins assembled into VLP with similar morphology. Compared to immunization with VLP, immunization with ELP-VLP induced significantly $(p<0.01)$ stronger VN antibody response and slightly $(p<0.05)$ stronger Cap-specific lgG antibody response, cytokine production and immunoprotection against PCV2 challenge.

Conclusion: A novel ELPylation platform for easy preparation of PCV2 VLP was established and the prepared ELPVLP was more immunogenic than VLP. The ELPylation technology could be used for other VLP preparation and the prepared ELP-VLP could be developed as a novel PCV2 subunit vaccine.
\end{abstract}

Keywords: PCV2 cap protein, ELP fusion expression, VLP preparation, Immunogenicity comparison

\footnotetext{
* Correspondence: sunh@yzu.edu.cn

${ }^{1}$ College of Veterinary Medicine, Jiangsu Co-innovation Center for Prevention and Control of Important Animal Infectious Diseases and Zoonoses, Yangzhou University, Yangzhou 225009, China

${ }^{2}$ Jiangsu Key Laboratory for High-Tech Research and Development of Veterinary Biopharmaceuticals, Jiangsu Agri-animal Husbandry Vocational College, Taizhou 225300, China
}

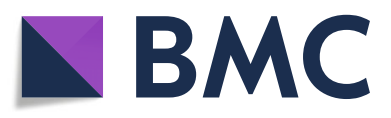

(c) The Author(s). 2020 Open Access This article is licensed under a Creative Commons Attribution 4.0 International License, which permits use, sharing, adaptation, distribution and reproduction in any medium or format, as long as you give appropriate credit to the original author(s) and the source, provide a link to the Creative Commons licence, and indicate if changes were made. The images or other third party material in this article are included in the article's Creative Commons licence, unless indicated otherwise in a credit line to the material. If material is not included in the article's Creative Commons licence and your intended use is not permitted by statutory regulation or exceeds the permitted use, you will need to obtain permission directly from the copyright holder. To view a copy of this licence, visit http://creativecommons.org/licenses/by/4.0/ The Creative Commons Public Domain Dedication waiver (http://creativecommons.org/publicdomain/zero/1.0/) applies to the data made available in this article, unless otherwise stated in a credit line to the data. 


\section{Background}

Porcine circovirus type 2 (PCV2) is the primary causative agent of several syndromes collectively known as porcine circovirus-associated disease (PCVAD) [1, 2]. Vaccination is an effective and economical method for the control of PCV2 infection. Currently, at least five commercial PCV2 vaccines are available in the international market, including the inactivated vaccine, capsid protein-based vaccines and chimerical PCV1/2 vaccine [3]. The inactivated vaccine is produced commonly in PK-15 cells with low yield due to poor propagation of PCV2 in PK-15 cells [4]. The capsid protein-based virus-like particle (VLP) vaccine can be produced in $E$. coli or baculovirus system, which requires expensive ultracentrifugation or chromatography for purification $[5,6]$. Therefore, reduction of PCV2 vaccine production cost is a key priority for veterinary research.

Elastin-like polypeptides (ELP) are derivatives of tropoelastin with the pentapeptide (Val-Pro-Gly-XaaGly) repeats, where Xaa can be any amino acid except proline. ELP have a unique property, inverse phase transition, which allows temperaturedependent reversible change from soluble monomers to insoluble aggregates $[7,8]$. Fusion of ELP with a target protein at the genetic level is now termed ELPylation, which has been exploited for several biomedical applications, such as recombinant protein purification [9], drug delivery [10] and protein halflife extension [11]. Like ELP, ELPylated proteins can be purified by inverse transition cycling (ITC) with the advantages of simplicity and low cost. Since they are derived from tropoelastin, ELP are biocompatible, non-toxic and non-immunogenic, making ELPylated proteins suitable for in vivo applications [12]. More recently, ELPylation has been used to improve the immunogenicity of influenza virus $M$ protein [13] and hemagglutinin [14].

In the present study, we explored the feasibility of ELPylation technology for simple purification and immunogenicity improvement of PCV2 VLP. The Cap protein of $\mathrm{PCV} 2 \mathrm{~b}$, together with the virus neutralizing (VN) epitopes of PCV2a, PCV2d and PCV2e, was expressed in E. coli as an ELPylated protein, and purified to a high purity with modified ITC. For the control purpose, the Cap protein was also expressed as a His-tagged protein and purified by nickel affinity chromatography. Both ELPylated and His-tagged Cap proteins assembled into VLP with similar morphology. Immunization of mice showed that ELPylated VLP was more immunogenic than His-tagged VLP. To our knowledge, this is the first study to demonstrate that ELPylation can be used for VLP preparation and immunogenicity improvement.

\section{Materials and methods}

\section{Vector construction}

ELP fusion expression vector pET-ELP was constructed by cloning ELP coding sequence into pET-30a (+) vector (Novagen, USA) with NdeI and SacI digestion [15]. The coding sequences for the Cap protein of PCV2b (GenBank accession: GQ359004) and the VN epitopes [16] of PCV2a (GenBank accession: GQ359003), PCV2d (GenBank accession: GU001710) and PCV2e (GenBank accession: GU001709) were adapted to $E$. coli codon usage using JAVA Codon Adaption Tool [17]. The synthetic sequence, with a tobacco etch virus (TEV) protease recognition signal introduced at the $5^{\prime}$ end, was cloned into pET-ELP vector with HindIII and XhoI digestion. For the comparison purpose, the synthetic sequence was amplified by PCR using the forward primer ( $5^{\prime}$-CAGTACATCAAAGCTAACTC-3') and the reverse primer (5'-CGGGTTCAGCGGCGGGTCTTT-3'), and cloned into pET-30a vector with NdeI and SalI digestion. The recombinant vectors were called pELP-Cap and pETCap (Fig. 1), and the expressed proteins were called ELP-Cap and Cap-His, respectively.

\section{Protein expression}

Both pELP-Cap and pET-Cap vectors were transformed individually into BL21 (DE3) E. coli. After growth for $5 \mathrm{~h}$ in $2 \times \mathrm{YT}$ medium ( $10 \mathrm{~g}$ yeast extract, $16 \mathrm{~g}$ tryptone, $5 \mathrm{~g} \mathrm{NaCl} / \mathrm{l}, \mathrm{pH} 7.2)$ containing kanamycin $(50 \mu \mathrm{g} / \mathrm{ml})$, the expression of the two fusion proteins was induced for $24 \mathrm{~h}$ at $20^{\circ} \mathrm{C}$ with $0.2 \mathrm{mM}$ IPTG (isopropyl $\beta$-D-thiogalactoside). After 10-min centrifugation at $5000 \mathrm{~g}$, the bacterial pellets were suspended in a lysis buffer $(50 \mathrm{mM}$ Tris-HCL, pH 8.0, 2 $\mathrm{mM}$ EDTA, $0.5 \%$ Triton X-100, $1 \mathrm{mM}$ DTT, 5\% glycerol), and disrupted two times at 1300 bar using High Pressure Cell Disruptor (JNBIO, China). After centrifugation for $15 \mathrm{~min}$ at $14,000 \mathrm{~g}$, the supernatants were collected for recombinant protein purification.

\section{Protein purification}

ELPylated Cap protein was purified by ITC as previously described [18] with slight modification. Briefly, after determination of the transition temperature and salt $(\mathrm{NaCl})$ concentration, ITC was performed in the presence of different concentrations of Triton X-100 and/or different concentrations of urea. After 5-min centrifugation at $14,000 \mathrm{~g}$ at room temperature, the protein pellet was washed with $1 \%$ Triton X-100 and $0.5 \mathrm{M}$ urea in $3 \mathrm{M}$ $\mathrm{NaCl}$. The residual endotoxin was removed by one round of Triton X-114 isothermal extraction as previously described [19]. His-tagged Cap protein was purified with His-Tagged Protein Purification Kit (CWBIO, China) under denatured conditions by following the manufacturer's instruction. Finally, the two purified 


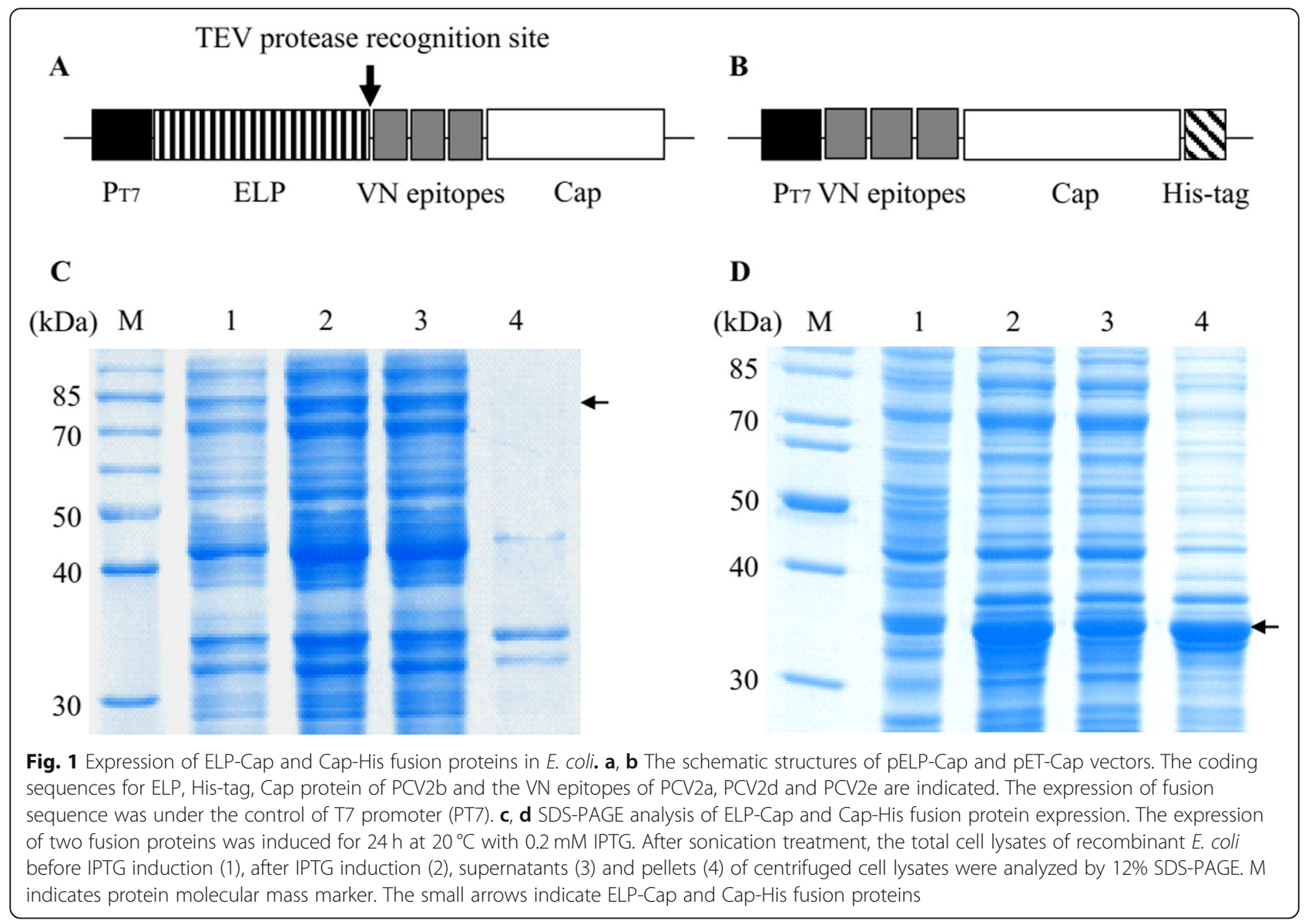

proteins were dialyzed in VLP assembling buffer $(50 \mathrm{mM}$ $\mathrm{Na}_{2} \mathrm{HPO}_{4}, 50 \mathrm{mM} \quad \mathrm{NaH}_{2} \mathrm{PO}_{4}, 500 \mathrm{mM} \mathrm{NaCl}, 1 \mathrm{mM}$ EDTA, $0.03 \%$ Tween 80, pH 6.5). After 5-min centrifugation at $12,000 \mathrm{~g}$, the supernatants were collected for further study.

\section{ELP tag cleavage}

The recombinant TEV protease was expressed in E. coli as a fusion protein with self-aggregating peptide ELK16 and purified by centrifugation in the presence of $0.5 \%$ Triton X-100 as previously described [19]. The purified ELPylated Cap protein $(100 \mu \mathrm{g})$ was digested overnight with the recombinant protease $(30 \mu \mathrm{g})$ as previously described [19]. After digestion, the active aggregates of TEV protease were removed by centrifugation and the cleaved ELP tag was removed by one round of ITC as described.

\section{Transmission electron microscopy}

Both ELPylated and His-tagged Cap proteins $(25 \mu \mathrm{g})$ were absorbed onto copper grids (400 meshes) for 2.5 min at room temperature. After drying gently with filter paper, the grids were stained with $3 \%$ phosphotungstic acid for $2.5 \mathrm{~min}$. The excess liquid was removed and the samples were observed under transmission electron microscope (Philips, Tecnai 12, Netherland) at an acceleration voltage of $75 \mathrm{kV}$.

\section{Western blotting}

Both ELPylated VLP (ELP-VLP) and His-tagged VLP (VLP) were separated on $12 \%$ SDS-PAGE and transferred to nitrocellulose membrane (Merck, USA) using a Mini-Protean ${ }^{\odot}$ Tetra Cell (Bio-Rad, USA) by following the manufacturer's instruction. The membrane was blocked for $2 \mathrm{~h}$ at $37{ }^{\circ} \mathrm{C}$ with $5 \%$ skim milk powder in PBST (0.1\% Tween 20 in PBS), and incubated for $1 \mathrm{~h}$ at $37^{\circ} \mathrm{C}$ with home-made pig anti-PCV2 serum (1:500). After three-time washing in PBST, the membrane was incubated for $30 \mathrm{~min}$ at $37^{\circ} \mathrm{C}$ with DeLyght ${ }^{800}$-labeled goat anti-pig IgG $(1: 10,000)$ (KPL, USA). The hybridization signal was scanned using Infrared Imaging System (Odyssey, USA) at $800 \mathrm{~nm}$ by following the manufacturer's instruction.

\section{Animal immunization and virus challenge}

Six-week-old BALB/c mice were purchased from the Center of Comparative Medicine, Yangzhou University. Eighteen mice were randomly divided into three groups 
(6 for each group). The mice in groups 1 and 2 were immunized intramuscularly with $200 \mu \mathrm{l}(50 \mu \mathrm{g})$ of ELP-VLP or VLP without use of adjuvant. The mice in group 3 were injected with the same volume of PBS as the negative control. The primarily immunized mice were boosted with the same dose of antigen at day 14 post immunization (dpi). The blood samples were collected at 7, 14, 21 and $28 \mathrm{dpi}$ for antibody detection. Three mice from each group were sacrificed at $28 \mathrm{dpi}$ for splenocyte isolation and cytokine detection. The remaining three mice in each group were challenged intraperitoneally with $2 \times 10^{3}$ $\mathrm{TCID}_{50}$ (50\% tissue culture infectious dose) of PCV2b. On days 7 and 14 post challenge (dpc), the serum samples were collected for PCV2 DNA detection.

\section{Indirect ELISA}

Bottom-flattened 96-well microplates were coated overnight at $4{ }^{\circ} \mathrm{C}$ with His-tagged Cap protein $(5 \mu \mathrm{g} / \mathrm{ml})$ in 0.1 $\mathrm{M}$ carbonate buffer ( $\mathrm{pH}$ 9.6). After blocking for $1 \mathrm{~h}$ at $4{ }^{\circ} \mathrm{C}$ with 5\% skim milk powder in PBST $(0.05 \%$ Tween 20 in PBS), the plates were incubated for $1 \mathrm{~h}$ at $37^{\circ} \mathrm{C}$ with the serum samples (1:100 in PBST). After three-time washing with PBST, HRP (horse radish peroxidase)-conjugated goat anti-mouse IgG (1:10,000 in PBST) (Sangon Biotech, China) was added and incubated for $1 \mathrm{~h}$ at $37^{\circ} \mathrm{C}$. After washing again, HRP signal was developed for $20 \mathrm{~min}$ with $\mathrm{TMB}$ (tetramethylbenzidine) substrate and $\mathrm{OD}_{450}$ values were measured on an ELISA reader.

\section{VN antibody test}

The VN antibody test was performed on 96-well microtitration plates using PK-15 cells as the indicator as previously described [20] with slight modification. Briefly, $100 \mu \mathrm{l}\left(4 \times 10^{5}\right)$ of cells was seeded to each well and grown for $24 \mathrm{~h}$ at $37^{\circ} \mathrm{C}$ in DMEM containing 10\% FBS (fecal bovine serum). Serum samples were heatinactivated for $30 \mathrm{~min}$ at $56^{\circ} \mathrm{C}$, and serially diluted twofold up to 1:512. Each dilution $(100 \mu \mathrm{l})$ and an equal volume of PCV2b (200 $\left.\mathrm{TCID}_{50}\right)$ were added and incubated for $60 \mathrm{~min}$ at $37^{\circ} \mathrm{C}$. After washing with PBS, $200 \mu \mathrm{l}$ of DMEM containing $2 \%$ FBS was added, and incubated for $24 \mathrm{~h}$ at $37^{\circ} \mathrm{C}$. After fixing with $80 \%$ cold acetone, immunofluorescence was performed using pig anti-PCV2 serum (1:500) as the first antibody and FITC-conjugated goat anti-pig IgG (1:1000) (Sigma, USA) as the second antibody. VN antibody titers were expressed as the highest dilutions in which no or higher than $80 \%$ reduction of virus replication was detected as compared to the virus control.

\section{Cytokine detection}

Each spleen sample from the immunized mouse was pushed through 1-ml syringe and centrifuged for $10 \mathrm{~min}$ at $1500 \mathrm{~g}$. The cell pellet was suspended with $500 \mu \mathrm{l}$ of
PBS and mixed with $3 \mathrm{ml}$ of red blood cell lysis buffer (Beyotime Biotechnology, China). After 5-min incubation at room temperature, the splenocytes were collected by 10 -min centrifugation at $1500 \mathrm{~g}$, washed two times with PBS and cultured $\left(5 \times 10^{6}\right.$ cells $\left./ \mathrm{ml}\right)$ overnight in RPMI 1640 medium (Hyclone, USA) supplemented with $10 \%$ FBS. After stimulation for $72 \mathrm{~h}$ at $37^{\circ} \mathrm{C}$ with Histagged Cap protein $(10 \mu \mathrm{g} / \mathrm{ml})$ or Con A $(10 \mu \mathrm{g} / \mathrm{ml})$ (Sigma, USA), the cell culture was centrifuged for 10 min at $3000 \mathrm{~g}$, and the supernatant was collected for cytokine detection. Interleukin 4 (IL-4), tumor necrosis factor- $\alpha$ (TNF- $\alpha)$ and interferon- $\gamma$ (IFN- $\gamma)$ were detected in triplicates using the ELISA Kits (Boster Bio, China) by following the manufacturer's instruction.

\section{Quantitative PCR}

The serum samples from immunized and PCV2challenged mice were extracted using MiniBEST Viral RNA/DNA Extraction Kit (TaKaRa, China) by following the manufacturer's instruction. PCV2 DNA copies were detected in triplicates using the Cap-specific forward primer (5-AAGGGCTGGGTTATGGTATG-3) and reverse primer (5-GAGTGGGCTCCAGTGCTGTTA-3). The quantitative PCR $(20 \mu \mathrm{l})$ was performed using $2 \mu \mathrm{l}$ of DNA template and SYBR Premix Ex Taq ${ }^{\mathrm{ma}} \mathrm{II}$ (TaKaRa, China) by following the manufacturer's instruction. The standard curve was generated using pMD-18 T vector (TaKaRa, China) containing the PCR-amplified Cap gene segment.

\section{Statistical analysis}

Statistical analysis was performed using SPSS Statistics 22 . The results were considered to be statistically significant at $p<0.05$ or extremely significant at $p<0.01$. For each separate set of data, at least three independent assays were performed and the results were represented as mean \pm standard deviation (SD).

\section{Results}

\section{Vector construction and protein expression}

To enhance the immunogenicity of PCV2b Cap protein, the coding sequence was fused with the coding sequences for the VN epitopes of PCV2a, 2d and 2e. To facilitate the protein purification, the synthetic sequence was cloned into pET-ELP vector and expressed as an ELPylated protein (Fig. 1a). For the comparison purpose, the synthetic sequence was cloned into $\mathrm{pET}-30 \mathrm{a}$ vector (Fig. 1b) and expressed as a His-tagged protein.

To facilitate the soluble protein expression, the expression of two fusion proteins was induced slowly at $20^{\circ} \mathrm{C}$ with $0.2 \mathrm{mM}$ IPTG. SDS-PAGE analysis showed that an expected $85-\mathrm{kDa}$ protein was expressed in pELP-Cap recombinant $E$. coli, which was present in the soluble fraction of centrifuged bacterial lysate (Fig. 1c). An expected 
35-kDa protein was expressed in pET-Cap recombinant $E$. coli, which was present mainly in the insoluble fraction of centrifuged bacterial lysate (Fig. 1d).

\section{ELPylated cap fusion protein was purified to high purity by modified ITC}

The transition temperature of ELPylated Cap protein was $26^{\circ} \mathrm{C}$ in $3 \mathrm{M} \mathrm{NaCl}$. After one cycle of ITC, SDSPAGE analysis showed that the Cap protein was purified to less than $50 \%$ purity (Fig. 2a). Then, ITC was performed in the presence of different concentrations of Triton X-100 or urea. SDS-PAGE analysis showed that the purity of ELPylated Cap protein could be significantly improved by including $1 \%$ Triton X-100 (Fig. 2b) or $0.5 \mathrm{M}$ urea into ITC (Fig. 2c) without significant loss of protein yield. Finally, the ITC was performed in the presence of $1 \%$ Triton $\mathrm{X}-100$ and $0.5 \mathrm{M}$ urea. SDSPAGE analysis showed that ELPylated Cap protein was purified to $94.3 \%$ purity with the modified ITC (Fig. 2d). His-tagged Cap protein was purified to $90.0 \%$ purity using nickel affinity chromatography under denatured condition (Fig. 2e). The performances of two protein purification methods are summarized in Table 1.

ELP tag could not be cleaved from ELPylated cap protein After overnight digestion, the active aggregates of TEV protease were removed by centrifugation and the cleaved ELP tag was removed by an additional round of ITC. SDS-PAGE analysis showed that the ELP tag could not be cleaved from ELPylated Cap protein.

\section{Both ELPylated and his-tagged cap proteins assembled into VLPs}

After dialysis in VLP assembling buffer, TEM analysis showed that both ELPylated and His-tagged Cap proteins assembled into VLPs (ELP-VLP or VLP hereafter) with diameter ranging from 15 to $20 \mathrm{~nm}$ (Fig. 3a). Except the slightly rough surface, the morphology of ELP-VLP was almost identical to that of VLP (Fig. 3b). Western blotting analysis showed that two forms of VLPs reacted positively with pig anti-PCV2 serum (Fig. 3c), suggesting the correct conformation of two Cap protein VLPs.

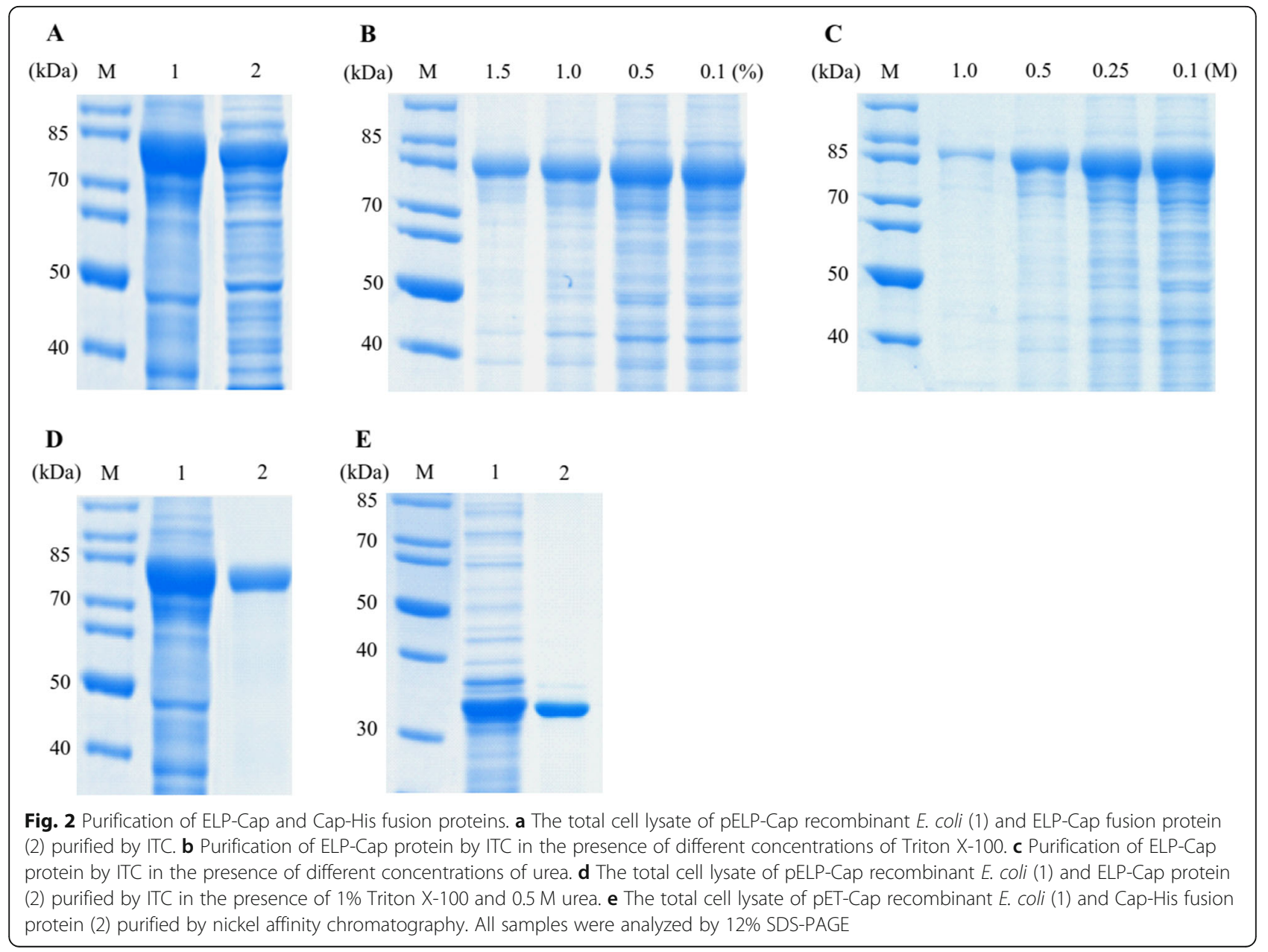


Table 1 Comparison of purification performances between inverse transition cycling and affinity chromatography

\begin{tabular}{llllll}
\hline Protein & Expression $(\mathrm{mg} / \mathrm{l})$ & Purity $(\%)$ & Recovery $(\%)$ & Yield $(\mathrm{mg} / \mathrm{l})$ & Purification time $(\mathrm{h})$ \\
\hline ELP-Cap & 56.16 & 94.3 & 74.6 & 41.91 & 2.5 \\
Cap-His & 49.37 & 90 & 60.77 & 30 & 23
\end{tabular}

\section{ELP-VLP induced stronger humoral response than VLP}

As compared to the control mouse serum, a significantly $(p<0.05)$ higher level of Cap-specific IgG antibody was detected in ELP-VLP or VLP immune serum as early as 7 dpi (Fig. 4a). From 14 dpi, the IgG antibody titers of the two vaccination groups, but not the control group, increased rapidly and reached to the highest levels by 28 dpi. For the inter-group comparison, the IgG antibody titer in ELP-VLP immune serum was slightly higher than that in VLP immune serum without significant difference (Fig. 4a).

Three mice from each group were sacrificed at $28 \mathrm{dpi}$ and the serum samples were assayed for VN antibody against PCV2. No VN antibody was detected in the control mouse serum. In contrast, a significantly $(p<0.01)$ amount of VN antibody was detected in ELP-VLP immune serum (1:16.8) or VLP immune serum (1:8.4). For the inter-group comparison, the average $\mathrm{VN}$ antibody titer in ELP-VLP immune serum was significantly $(p<$ 0.01) higher than that in VLP immune serum (Fig. 4b).

\section{ELP-VIP induced stronger cytokine response than VLP}

Three mice from each group were sacrificed at $28 \mathrm{dpi}$ and the splenocytes were isolated for cytokine detection. After 72-h stimulation with VLP, the cell culture media were assayed for TNF- $\alpha$, IFN- $\gamma$ and IL-4. As compared with the control group, a significant $(p<0.01)$ amount of TNF- $\alpha$ was detected in ELP-VLP $(1100 \mathrm{pg} / \mathrm{ml})$ or VLP $(870 \mathrm{pg} / \mathrm{ml})$ vaccination group (Fig. 5a). Similarly, a significant $(p<0.01)$ amount of IFN- $\gamma$ was detected in ELPVLP $(570 \mathrm{pg} / \mathrm{ml})$ or VLP $(360 \mathrm{pg} / \mathrm{ml})$ vaccination group (Fig. 5b). Finally, a significant $(p<0.01)$ amount of IL-4 was detected in ELP-VLP $(620 \mathrm{pg} / \mathrm{ml})$ or VLP $(580 \mathrm{pg}$ / $\mathrm{ml}$ ) vaccination group (Fig. $5 \mathrm{c}$ ). For the inter-group comparison, the three cytokine responses of ELP-VLP vaccination group were slightly higher than that of VLP vaccination group without significant difference. The VLP-stimulated cytokine responses were slightly stronger than that stimulated with Con A, suggesting the specificity of three cytokine responses after ELP-VLP or VLP immunization.

\section{ELP-VLP induced stronger immunoprotection than VLP}

The three remaining mice in each group were challenged with PCV2 at $28 \mathrm{dpi}$ and the serum samples were assayed for the viral DNA copies by quantitative PCR. At $7 \mathrm{dpc}$, the viral DNA copy number in ELP-VLP (4.21 $\log 10 / \mathrm{ml})$ or VLP $(4.98 \log 10 / \mathrm{ml})$ immune serum was significantly $(p<0.05)$ lower than that $(6.01 \log 10 / \mathrm{ml})$ in the control serum (Fig. 6). By $14 \mathrm{dpc}$, the viral DNA copy number in ELP-VLP (3.21 $\log 10 / \mathrm{ml})$ or VLP (3.72 $\log 10 / \mathrm{ml}$ ) immune serum was extremely significantly

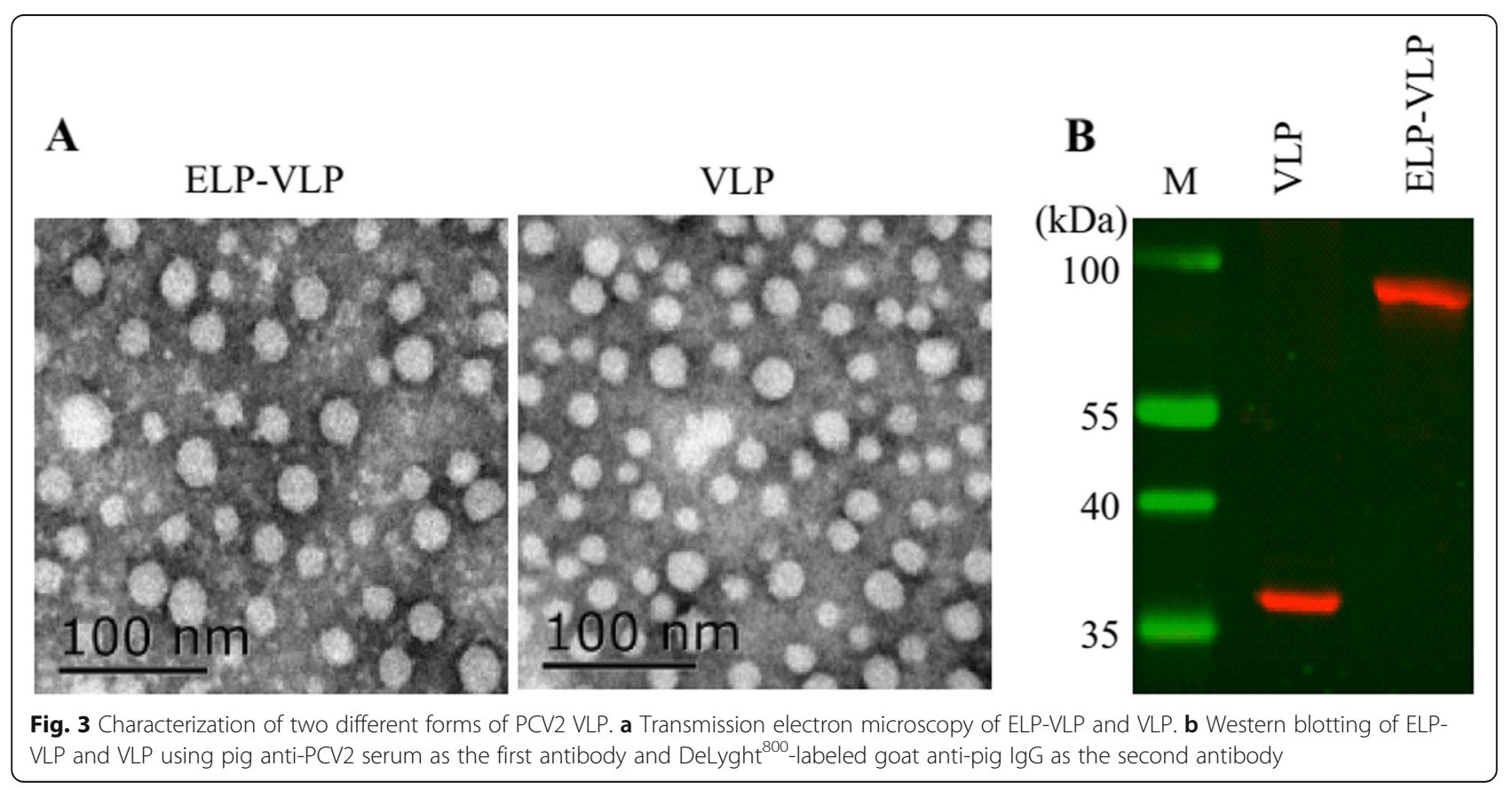



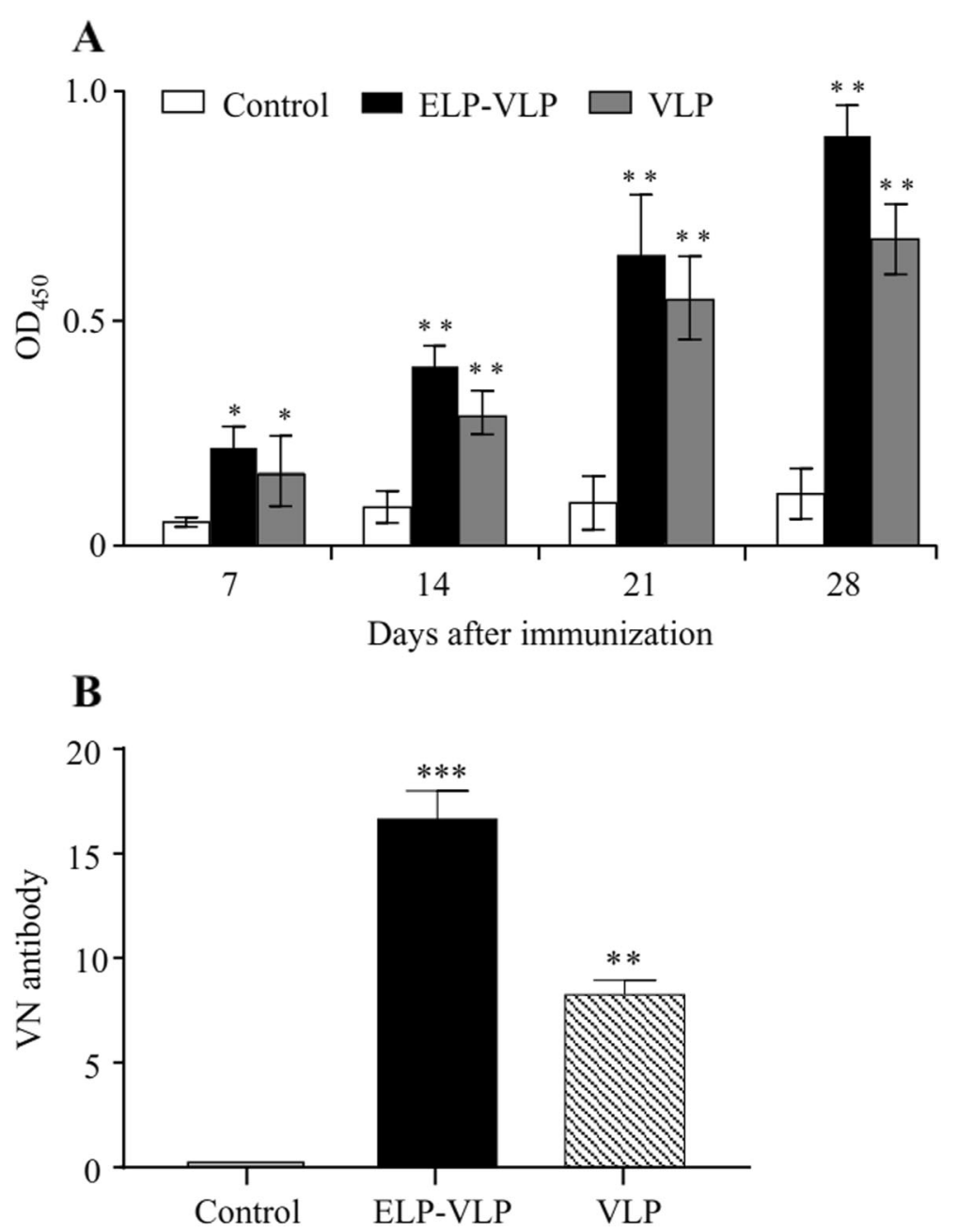

Fig. 4 Comparison of the antibody responses after immunization with two different forms of VLPs. Mice were immunized two times with the same dose of ELP-VLP or VLP without use of adjuvant. a The serum samples were collected from the immunized and control mice at indicated time and analyzed for the Cap-specific lgG antibody. $\mathbf{b}$ The serum samples were collected from the immunized and control mice at $28 \mathrm{dpi}$ and analyzed for PCV2 VN antibody. ${ }^{*},{ }^{* *}$ and ${ }^{* * *}$ indicate $p<0.05, p<0.01$ and $p<0.001$ as compared with the control group

$(p<0.01)$ lower than that $(5.52 \log 10 / \mathrm{ml})$ in the control serum (Fig. 6). For the inter-group comparison, the viral DNA copy number in ELP-VLP immune serum was slightly lower than that in VLP immunization serum without significant difference.

\section{Discussion}

ELP can undergo temperature-dependent inverse phase transition from soluble monomers to insoluble aggregates, and thus ELPylated proteins can be purified simply by ITC $[7,8]$. The primary objective of this study was to explore the feasibility of ELPylation technology for preparation of PCV2 VLP vaccine. To this end, the Cap protein of PCV2b, together with the VN epitopes of PCV2a, PCV2d and PCV2e, was expressed in E. coli as an ELPylated or His-tagged protein. For ITC to be useful, ELPylated Cap protein must be expressed as a soluble protein.
Therefore, the expression of the two fusion proteins was induced slowly at low temperature to facilitate soluble protein expression. As expected, ELPylated Cap protein was expressed as a soluble protein. In contrast, His-tagged Cap protein was expressed as insoluble inclusion bodies under the same conditions. This data suggests that the ELP tag could improve the solubility of recombinant Cap protein of PCV2. After one cycle of ITC, however, the purity of purified ELPylated Cap protein was less than $50 \%$, which could not be improved by repeated ITC. Since ELP-mediated ITC can be performed in the presence of low concentrations of mild detergents [21], we modified the ITC by inclusion of $1 \%$ Triton X-100 and $0.5 \mathrm{M}$ urea. By using the modified ITC, ELPylated Cap protein was purified to more than $90 \%$ purity, which was comparable to that of His-tagged Cap protein purified by nickel affinity chromatography. 

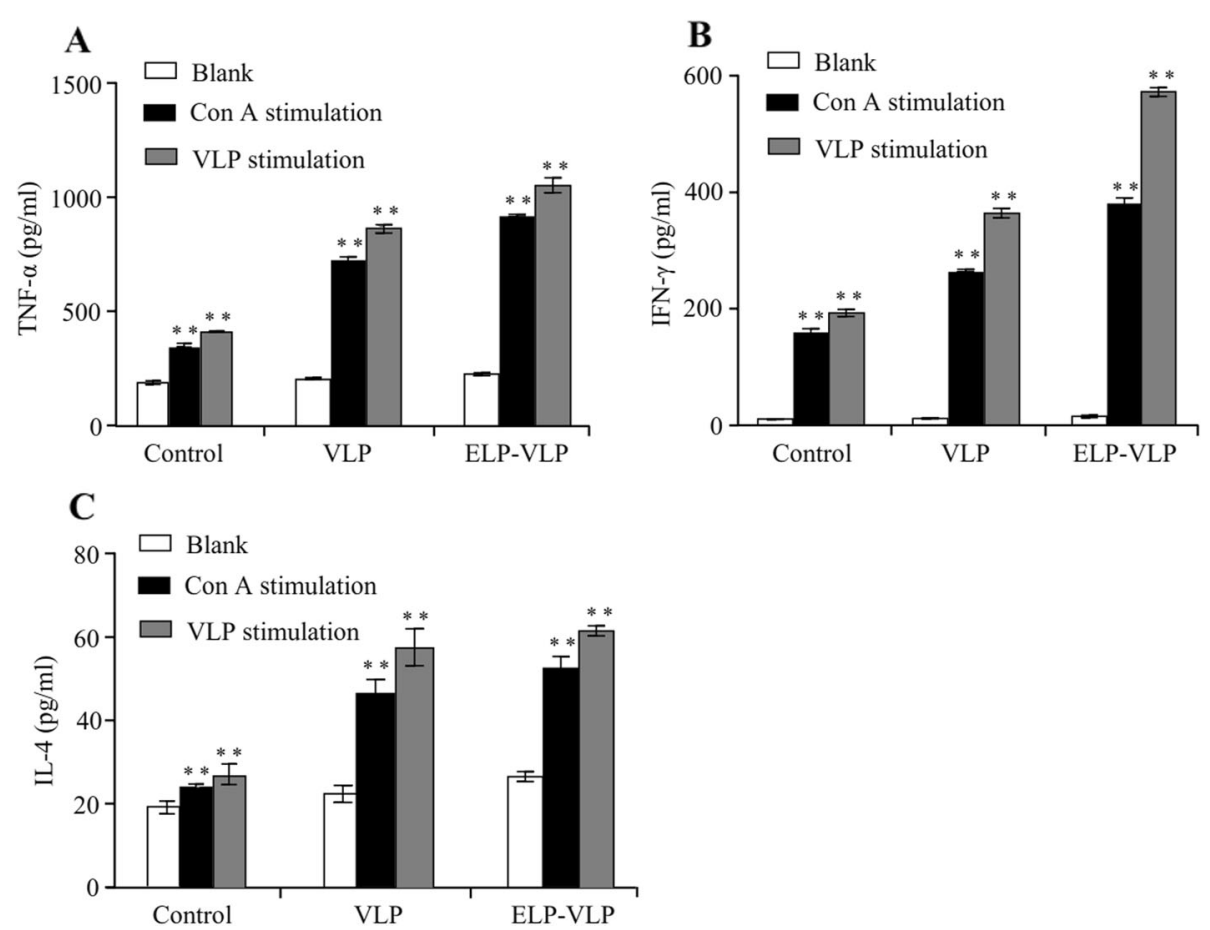

Fig. 5 Comparison of cytokine responses after immunization with two different forms of VLPs. Three mice from each group were sacrificed at 28 dpi for splenocyte isolation. After 72-h stimulation with VLP or Con A, the splenocyte culture media were assayed for three cytokines using commercial ELISA kits. ${ }^{* *}$ indicates $p<0.01$ as compared with the control group

After obtaining the purified fusion protein, we tried to cleave ELP tag from ELPylated Cap protein with recombinant TEV protease. Unexpectedly, ELP tag was unable to be cleaved from ELPylated Cap protein. To find the possible reason for the incapability of ELP tag cleavage, we

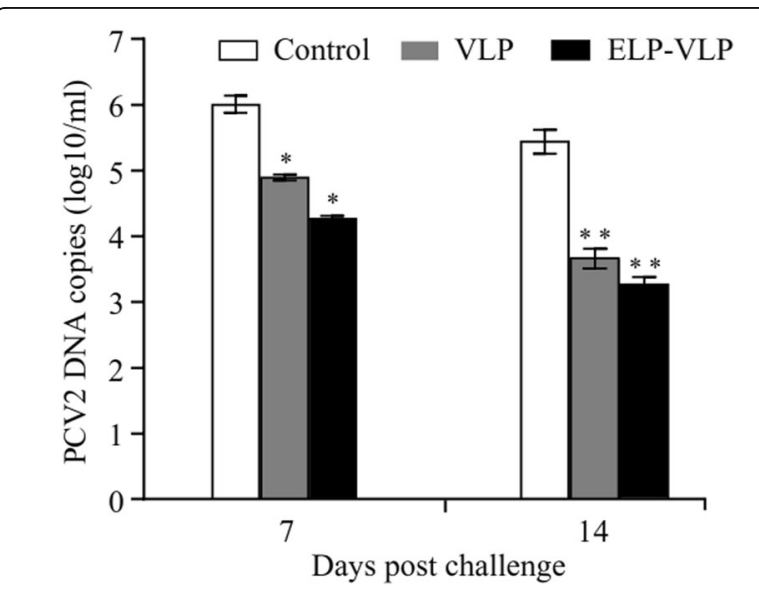

Fig. 6 Comparison of immunoprotection of two different forms of VLP against PCV2 challenge. After two-time immunization with ELPVLP or VLP, three mice from each group were challenged with PCV2b at $28 \mathrm{dpi}$. The serum samples were collected from the immunized and control mice at indicated times and assayed for PCV2 DNA copies by quantitative PCR. * and ${ }^{* *}$ indicate $p<0.05$ and $p<0.01$ as compared with the control group analyzed the structure of ELPylated Cap protein by TEM. As expected, ELPylated Cap protein assembled into VLP with morphology similar to VLP. This data confirmed that ELP do not interfere with recombinant protein folding [22]. Therefore, the incapability of ELP tag cleavage could be explained by burring of TEV protease recognition site inside of ELP-VLP. Since ELP can improve the immunogenicity of recombinant protein vaccines by protecting against antigen degradation [13, 14], the cleavage of ELP tag from ELP-VLP was unnecessary.

Currently, there is no consensus for PCV2 vaccine evaluation in animal models. Although some research groups have reported that mouse models provide only limited utility in understanding of PCVAD, mouse models have been used widely for elucidation of in vivo behaviors of the virus-host interaction and PCV2 vaccine immunogenicity [23]. Therefore, in this study we compared the immunogenicities between ELP-VLP and VLP using a mouse model. After immunization with ELPVLP or VLP, the Cap-specific IgG antibody response was detectable as early as $7 \mathrm{dpi}$, which was significantly enhanced by boosting with the same form of VLPs. Although the actual amount of Cap antigen in ELP-VLP was significantly less than that in VLP due to the significant difference in fusion tag length, immunization with the same dose of ELP-VLP induced even higher specific IgG response than with VLP. Importantly, the VN 
antibody titer induced by ELP-VLP was significantly $(p<0.01)$ higher than that by VLP. In addition, both Th1 (TNF- $\alpha$, IFN- $\gamma$ ) and Th2 (IL-4) cytokine responses induced by ELP-VLP were also stronger than that by VLP, suggesting that ELP-VLP could promote the balanced Th1/Th2 response. Most importantly, immunization with ELP-VLP could provide the stronger protection against PCV2 challenge than with VLP. These data suggest that ELP-VLP can be developed further as a novel subunit vaccine against PCV2 infection.

\section{Conclusion}

In this study, an ELPylation technology was established for easy preparation of PCV2 VLP vaccine. The established technology could be used for other VLP preparation and the ELP-VLP prepared could be developed further as a novel PCV2 subunit vaccine.

\section{Abbreviations}

PCV2: Porcine circovirus type 2; PCVAD: Porcine circovirus-associated disease: ELP: Elastin-like polypeptide; ITC: Inverse transition cycling; VLP: Virus-like particles; TEV: Tobacco etch virus; IPTG: Isopropyl $\beta$-D-thiogalactoside; TEM: Transmission electron microscopy; dpi: Days post infection; dpc: Days post challenge; ELISA: Enzyme-linked immunosorbent assay; VN: Virus neutralization; $\mathrm{TCID}_{50}$ : 50\% tissue infectious dose; FBS: Fetal bovine serum; IL4: Interneukine-4; TNF-a: Tumor necrosis factor-a; IFN- - : Interferon- $\gamma$

\section{Acknowledgements}

Not applicable.

\section{Authors' contributions}

LYY performed vector construction, protein purification, animal immunization and challenge; WYJ, CJ, ZXH and LHP helped in vector construction and protein purification; ZXY and XXL helped in material preparation; SHC designed this study and polished the manuscript. The author(s) read and approved the final manuscript.

\section{Funding}

This work was funded by the National Key R\&D Program of China (2017YFD0502303 and 2018YFC0840404-3), and the Priority Academic Program Development of Jiangsu Higher Education Institutions (PAPD).

\section{Availability of data and materials}

All data and materials involved in this study are available if required.

\section{Ethics approval and consent to participate}

This research, including the procedure and protocol of animal immunization, sample collection and processing, was carried out according to the recommendations in the Guide for the Care and Use of Laboratory Animals of the Yangzhou University. The protocol was approved by Medical Experimental Animal Center of Jiangsu Province (Permit Number: 2140880).

\section{Consent for publication}

Not applicable.

\section{Competing interests}

The authors declare that they have no conflict of interest.

Received: 25 August 2019 Accepted: 2 June 2020

Published online: 09 June 2020

\section{References}

1. Chae C. A review of porcine circovirus 2-associated syndromes and diseases. Vet J. 2005;169:326-36.

2. Opriessnig T, Meng XJ, Halbur PG. Porcine circovirus type 2 associated disease: update on current terminology, clinical manifestations, pathogenesis, diagnosis, and intervention strategies. J Vet Diagn Investig. 2007;19:591-615.

3. Chae C. Commercial porcine circovirus type 2 vaccines: efficacy and clinical application. Vet J. 2012;194:151-7.

4. Zhu Y, Lau A, Lau J, Jia Q, Karuppannan AK, Kwang J. Enhanced replication of porcine circovirus type 2 (PCV2) in a homogeneous subpopulation of PK15 cell line. Virol. 2007;369:423-30.

5. Vicente T, Roldão A, Peixoto C, Carrondo MJ, Alves PM. Large-scale production and purification of VLP-based vaccines. J Invertebr Pathol. 2011; 107(Suppl):S42-8.

6. Wu PC, Chen TY, Chi JN, Chien MS, Huang C. Efficient expression and purification of porcine circovirus type 2 virus-like particles in Escherichia coli. J Biotechnol. 2016;220:78-85.

7. Shamji MF, Betre H, Kraus VB, Chen J, Chilkoti A, Pichika R, Masuda K, Setton $\mathrm{LA}$. Development and characterization of a fusion protein between thermally responsive elastin-like polypeptide and interleukin-1 receptor antagonist. Arthritis Rheum. 2007;56:3650-61.

8. Urry DW. Free energy transduction in polypeptides and proteins based on inverse temperature transitions. Prog Biophys Mol Biol. 1992;57:23-57.

9. Meyer DE, Chilkoti A. Purification of recombinant proteins by fusion with thermally-responsive polypeptides. Nat Biotechnol. 1999;17:1112-5.

10. McDaniel JR, Callahan DJ, Chilkoti A. Drug delivery to solid tumors by elastin-like polypeptides. Adv Drug Deliv Rev. 2010;62:1456-67.

11. Hearst SM, Shao Q, Lopez M, Raucher D, Vig PJS. The design and delivery of PKA inhibitory polypeptide to treat SCA1. J Neurochem. 2014;131:101-4.

12. Yeboah A, Cohen Rl, Rabolli C, Yarmush ML, Berthiaume F. Elastin-like polypeptides: a strategic fusion partner for biologics. Biotechnol Bioeng. 2016;113:1617-27.

13. Ingrole RS, Tao W, Tripathy JN, Gill HS. Synthesis and immunogenicity assessment of elastin-like polypeptide-M2e construct as an influenza antigen. Nano Life. 2014;4:1450004.

14. Phan HT, Pohl J, Floss DM, Rabenstein F, Veits J, Le BT, Chu HH, Hause G, Mettenleiter T, Conrad U. ELPylated haemagglutinin produced in tobacco plants induce potentially neutralizing antibodies against $\mathrm{H} 5 \mathrm{~N} 1$ viruses in mice. Plant Biotechnol J. 2013;11:582-93.

15. Zong $Y$, Tan $X$, Xiao J, Zhang $X$, Xia $X$, Sun $H$. Half-life extension of porcine interferon-a by fusion to the lgG-binding domain of streptococcal $G$ protein. Protein Expr Purif. 2019;153:53-8.

16. Huang LP, Lu YH, Wei YW, Guo LJ, Liu CM. Identification of one critical amino acid that determines a conformational neutralizing epitope in the capsid protein of porcine circovirus type 2. BMC Microbiol. 2011;11:188.

17. Grote A, Hiller K, Scheer M, Münch R, Nörtemann B, Hempel DC, Jahn D. JCat: a novel tool to adapt codon usage of a target gene to its potential expression host. Nucleic Acids Res. 2005;33(Web Server issue):W526-31.

18. Liu WJ, Wu Q, Xu B, Zhang XY, Xia XL, Sun HC. Single-step purification of recombinant proteins using elastin-like peptide-mediated inverse transition cycling and self-processing module from Neisseria meningitides FrpC. Protein Expr Purif. 2014;98:18-24.

19. Li GY, Xiao ZZ, Lu HP, Li YY, Zhou XH, Tan X, Zhang XY, Xia XL, Sun HC. A simple method for recombinant protein purification using self-aggregating peptide-tagged tobacco etch virus protease. Protein Expr Purif. 2016;128:8692.

20. Pogranichnyy RM, Yoon KJ, Harms PA, Swenson SL, Zimmerman JJ, Sorden $\mathrm{SD}$. Characterization of immune response of young pigs to porcine circovirus type 2 infection. Viral Immunol. 2000;13(2):143-53.

21. Thapa A, Han W, Simons RH, Chilkoti A, Chi EY, López GP. Effect of detergents on the thermal behavior of elastin-like polypeptides. Biopolymers. 2013;99:55-62.

22. Floss DM, Sack M, Stadlmann J, Rademacher T, Scheller J, Stoger E, Fischer $\mathrm{R}$, Conrad U. Biochemical and functional characterization of anti-HIV antibody-ELP fusion proteins from transgenic plants. Plant Biotechnol J. 2008;6:379.

23. Ouyang T, Liu XH, Ouyang HS, Ren LZ. Mouse models of porcine circovirus 2 infection. Animal Model Exp Med. 2018;1:23-8.

\section{Publisher's Note}

Springer Nature remains neutral with regard to jurisdictional claims in published maps and institutional affiliations. 